\title{
Querido Diego, te abraza Quiela de Elena Poniatowska y la epístola como cuestionamiento del pensamiento patriarcal
}

\author{
BLADIMIR RUIZ*
}

Resumen:

En este trabajo exploro la inscripción de la novela Querido Diego, te abraza Quiela de Elena Poniatowska en el contexto de una crítica literaria feminista dirigida a desmantelar los complejos procesos a través de los cuales se sustenta la hegemonía patriarcal. En esta dirección se analiza aquí la articulación que existe entre géneros literarios y poder, y las estrategias de desestabilización que se observan en procesos de manipulación textual y de creación literaria aparentemente neutrales. La reflexión propuesta gira en torno a la revisión de esta novela como texto epistolar, las implicaciones que esto acarrea, la caracterización de Quiela, el personaje de la novela, como sujeto, y, muy particularmente, el cuestionamiento que la escritora hace del canon al intervenir, para la creación de su texto ficcional, el texto biográfico escrito por Beltram Wolfe titulado La fabulosa vida de Diego Rivera.

Palabras clave:

Novela mexicana contemporánea, feminismo y literatura, narrativa femenina latinoamericana, género epistolar, Poniatowska.

\footnotetext{
${ }^{*}$ Profesor-investigador. Trinity University.
} 
La crítica literaria ha sufrido cambios y reorientaciones de gran magnitud en los últimos treinta años. Las razones de ello son de naturaleza múltiple y compleja, pero sin duda la irrupción de nuevas corrientes ideológicas dentro del panorama crítico es, si no la principal, una de las más importantes. En tal sentido, el feminismo, como sistema de pensamiento radical, ha posibilitado una revisión de los valores y estructuras que soportan y conforman nuestra configuración del mundo en general. Al hacerlo, inició un proceso de deconstrucción que tiene por finalidad el cuestionamiento y redefinición de los sistemas de poder que sustentan la ideología patriarcal. En terrenos de la literatura, el feminismo ha posibilitado una nueva lectura de los textos bajo las luces de sus implicaciones ideológicas. De esta manera, la crítica feminista ha postulado que la opresión estructural de las mujeres en el sistema del patriarcado encuentra su equivalente dentro del campo de la representación simbólica. Más aún, las distintas posiciones feministas -pues no estamos en presencia de un sistema de pensamiento monolíticohan puesto en tela de juicio la canonización de textos literarios bajo la premisa de que la misma responde a una evaluación formulada desde las instancias centrales del poder. Con ello, no sólo se ha buscado redimensionar las interpretaciones que se han hecho sobre estos textos, sino también, y fundamentalmente, se ha vuelto la mirada hacia otros (producidos por mujeres) que han sido olvidados o despreciados, dada su condición marginal.

Estas consideraciones iniciales conllevan a un punto crucial dentro de la crítica literaria de los últimos años: la de si existe o no una escritura femenina. Semejante asunto escapa de los alcances de este escrito, cuyos objetivos específicos todavía no he presentado. No obstante, es menester señalar que para muchas feministas aseverar que existe una escritura femenina significa aceptar la lógica binaria que ha regido desde siempre la ideología patriarcal. ${ }^{1}$ Helene

${ }^{1}$ Recuérdese que una parte del trabajo de Héléne Cixous consiste en la identificación del pensamiento binario del patriarcado. Al respecto, Cixous apunta que hay un conjunto de oposiciones binarias que han estructurado el pensamiento occidental y gobernado su práctica política (actividad/pasividad, sol/luna, cultura/naturaleza, pensamiento/emoción, logos/pathos, etc.). Igualmente sostiene que estas oposiciones son subyacentes a la oposición fundamental hombre/mujer y que cada una puede ser analizada como una jerarquía en la cual el 
Cixous considera peligroso hablar de escritura masculina o femenina. Más aún: "she thus warns against the danger of confusing the sex of the author with the sex' of the writing" (Moi 108). ${ }^{2}$ Pese a estas observaciones, en ocasiones se ha intentado definir la escritura femenina como una suerte de reacción en contra de la escritura masculina. Al hacerlo se ha establecido, paradójicamente, una situación de dependencia que en apariencia desea romperse. Sin duda nos enfrentamos a muchos postulados críticos reduccionistas, como apunta Alicia Borinsky, pues este tipo de ejercicio toma "textos escritos por hombres y textos escritos por mujeres como si fueran dos sistemas literarios totalmente distintos" (González, La sartén 14). En el fondo toda esta discusión tiene su correlato en otro debate asimismo esencialista: aquél que pretende dilucidar lo que una mujer es. Y evidentemente lo único cierto en torno a la mitad de la población humana (y éste es, como ironía, el mayor de los esencialismos) sólo puede ser planteado en términos biológicos, pues el resto pertenece al reino de lo cultural. Quizás no tenga mucho sentido esta discusión, más allá del ejercicio intelectual mismo, más todavía si tomamos en consideración que muchas de estas posturas radicales han cedido el paso a posiciones más abarcadoras. De allí que preguntarnos si la escritura de cualquier escritor (a) -la insistencia en la doble posibilidad genérica es importante en un texto que discute estos asuntos- es masculina o femenina nos lleve por muchos caminos críticos interesantes, pero ninguno conclusivo. En cualquiera de los casos -y en este punto este texto crítico se inclina por posturas como la de Julia Kristeva- aseverar

lado "femenino" siempre es visto como negativo. El problema es que el sistema binario es un campo de batalla en el cual se registra una lucha constante por supremacía significativa. Al final la derrota es equiparada con pasividad, y el triunfo, por supuesto, con actividad. De más está decir que dentro del patriarcado el varón siempre es el vencedor. En todo caso, el proyecto teórico de esta pensadora parte de la necesidad de cancelar esta ideología logocéntrica por proclamar a la mujer como fuente de vida, poder y energía, por dar la bienvenida al advenimiento de un lenguaje femenino que subvierta incesantemente los esquemas binarios patriarcales dentro de los cuales el logocentrismo deviene en falocentrismo en un intento por oprimir y silenciar a las mujeres.

${ }^{2}$ [ella, por lo tanto, advierte sobre el peligro de confundir el sexo del autor con el 'sexo' de la escritura]. 
que un texto es masculino o femenino implica de alguna manera aceptar que el lenguaje intrínsecamente es sexista. Y tal y como esta pensadora asevera, este fenómeno poco o nada tiene que ver con la naturaleza intrínseca del lenguaje mismo. Es, por el contrario, el efecto de la relación de poder dominante entre los sexos. ${ }^{3}$ De allí que pierda fuerza cualquier intento de caracterización genérica en la escritura de cualquier autor (a) y de que tenga más sentido hablar de lo que Beatriz González llama un discurso androcéntrico (o uno no-androcéntrico, opuesto a aquél) que funciona relegando a los márgenes de lo no significativo todo lo que considera pertinente a la jerarquía central. Opera a través de exclusiones y

[...] valora positivamente sólo aquello que le concierne, no es propio de cualquier ser humano de sexo masculino, sino de aquellas prácticas sociales y discursivas de aquellos seres humanos que se sitúan en el centro hegemónico de la vida social, autodefinen sus valores como superiores y, para perpetuar su hegemonía, imponen a los otros su perspectiva mediante la persuasión, disuasión y, finalmente, la coerción. (González 109)

Este largo preámbulo nos permite entrar de lleno en el estudio de un texto escrito por una mujer y protagonizado por otra: Querido Diego, te abraza Quiela de Elena Poniatowska. Interesa en este trabajo la revisión de esta novela como texto epistolar, las implicaciones que esto acarrea; la caracterización de Quiela, el personaje de la novela, como sujeto; y, muy particularmente, el cuestionamiento que la escritora hace del canon al intervenir, para la creación de su texto ficcional, el texto biográfico escrito por Beltram Wolfe titulado La fabulosa vida de Diego Rivera. Explicitando estas consideraciones, quisiera explorar cómo su inscripción en el género epistolar ubica a la novela en una discusión interesante: ¿Quién

3 Kristeva sostiene, en relación a estas observaciones, que si las mujeres ganan su tan ansiada lucha en contra del patriarcado, el signo lingüístico seguirá siendo el lugar en el cual esta lucha y cualquier otra se manifiesten. En ese y en cualquier otro caso se trata de cambios de contextos (palabra clave, dentro de esta parte del pensamiento kristevano). 
escribe y para quién? ¿Desde dónde se escriben las cartas y la novela? ¿Qué intención parece esconderse detrás de esta recreación de una parte de la vida de dos personajes con un referente concreto a nivel histórico? Asimismo, es importante visualizar cómo desde este género "menor" (novela epistolar) se enarbola una crítica a procesos culturales que ubican figuras y géneros retóricos en un lugar de superioridad y cómo estos procesos de evaluación están conectados con un sistema que privilegia tanto en terrenos concretos como simbólicos lo masculino sobre lo femenino.

Elena Poniatowska quizás sea hoy día la más destacada (o la más conocida) de las escritoras mexicanas. Su carrera como escritora muestra cómo las tradicionales fronteras entre formas literarias y periodísticas se diluyen para crear una escritura en la cual se intenta dar una perspectiva crítica de la realidad contemporánea mexicana, a través de la recuperación de versiones silenciadas de eventos y de voces marginales que, desde la periferia, intentan desestabilizar el status quo. Los textos de Poniatowska son escritos renuentes a la clasificación genérica, es decir, son discursos híbridos en los cuales se combinan realidad y ficción y se utilizan diferentes registros lingüísticos y formas literarias. Como señala Beth Jorgensen en la introducción de su libro, todas estas innovaciones formales corresponden a las exigencias de su investigación en torno a la problemática de clase, género y diferencia étnica, a las luchas de las mujeres y de los pobres por justicia socio-económica y a los mecanismos de represión que generan tales luchas. Muchos críticos han apuntado que desde cierto punto de vista la historia de la escritura de Elena Poniatowska es la historia de su encuentro con México y, citando textualmente a Jorgensen, "her texts inscribe the ever-changing relationship between her voice end the voice of her compatriots" (Jorgensen xix). ${ }^{4}$

${ }^{4}$ [Sus textos asientan la siempre cambiante relación entre su voz y la voz de sus compatriotas]. Elena Poniatowska no nació en México, sino en París (en 1932); su padre era un francés de origen polaco y su madre, que había nacido en Francia, era hija de terratenientes mexicanos. Se crió, pues, en Europa y volvió a México a los diez años para continuar sus estudios en una academia británica llamada Windsor School, y después en el liceo franco-americano de la capital. Posteriormente viajaría a los Estados Unidos para culminar su educación en un convento católico (esto es, su preparación para el matrimonio). Aprendió el es- 
La novela que nos ocupa, Querido Diego, te abraza Quiela, aparece en 1976 y, a primera vista, parece alejarse considerablemente del tipo de literatura de compromiso social con la que hasta ese momento Elena Poniatowska había sido relacionada; ${ }^{5}$ es decir, en el texto no hay representación testimonial como tal, tampoco parece haber denuncia política ni social y, a nivel formal, no está basada en declaraciones orales ni en entrevistas previas. Su fuente, como ya sabemos, es escrita. Sería entonces fácil concluir a priori, como de hecho ocurrió con la recepción crítica inmediata a la publicación de la obra, que esta novela es una especie de anomalía dentro de la producción de la escritora. No obstante, una mirada un poco más aguda permitirá corregir esa primera impresión: Poniatowska sigue preocupada por mujeres olvidadas, por seres marginados que intentan conseguir un espacio en el que su voz pueda ser escuchada. Al respecto John Berry afirma en su estudio sobre este texto que la escritora mexicana sigue manejando en la novela los mismos temas: los motivos que impulsan a una mujer a la lucha en contra del aislamiento al que la somete un mundo dominado por el hombre, su preocupación en torno al amor y las dificultades que con él se originan, los problemas de la comunicación entre los seres humanos y, sobre todo, su preocupación constante por los olvidados.

Por otra parte, en lo formal Poniatowska permanece fiel a muchas de sus inclinaciones. Querido Diego es una composición textual en la cual se mezclan la realidad y la invención. Sus personajes tienen referencialidad histórica y lo mismo podemos decir de su premisa anecdótica. Ésta se basa en la relación entre Diego Rivera y la pintora rusa Angelina Beloff, quienes se conocieron en Brujas en

pañol, según sus propias declaraciones, por medio de las sirvientas de la casa, quienes la introdujeron real e indirectamente en la "verdadera realidad" del pueblo mexicano.

5 Tómese en cuenta que previamente a la publicación de esta novela había escrito obras como Hasta no verte Jesús mío (1969) y La noche de Tlatelolco (1971), textos de marcado carácter testimonial que son, en el primer caso, el resultado de entrevistas dirigidas a mostrar la vida de una mujer pobre mexicana y, en el segundo, los eventos acaecidos entre julio y diciembre de 1968, en un intento por reconstruir una historia que el gobierno mexicano trató de suprimir de las páginas del discurso histórico oficial. 
1909, se enamoraron y, más tarde, se mudaron a París. En 1916 tuvieron un hijo que murió a temprana edad. Un año después de este suceso Diego abandonó a Angelina para vivir con otra pintora rusa con quien procreó una niña. Finalmente, en 1921 el pintor se separó en forma definitiva de ella para regresar a México, no sin antes haberle prometido que mandaría a buscarla cuando alcanzara cierto bienestar económico. Se resalta que la novela solamente registra, por medio de un grupo de cartas que van desde el 19 de octubre de 1921 hasta el 22 de julio de 1922, la espera de Quiela y su revisión dolorosa de un presente agobiante lleno de fantasmas del pasado y de esperanzas por un futuro prometido pero cada día más inalcanzable. Para la elaboración de este texto Elena Poniatowska admite haber consultado La fabulosa vida de Diego Rivera de Bertram Wolfe en el que encontró transcritas dos cartas de Angelina, así como información mediatizada por la voz autoritaria del biográfo de Rivera. ${ }^{6}$ Con todo esto la escritora construyó su propio texto en el cual la voz de Angelina adquiere supremacía a partir de la fragmentación y dispersión de la información encontrada y de la invención de muchos otros aspectos. De esta manera, lo expresado por la Quiela de las cartas en Querido Diego no es sólo lo que Angelina expresa en sus cartas sino también lo que Wolfe afirma y opina (en lo personal o a partir de otros informantes) en su texto biográfico.

Querido Diego, te abraza Quiela, entonces, puede ser registrada, desde cierto punto de vista, como una novela epistolar y como tal se nos presenta como un discurso narrativo fragmentado. En la misma dirección, como novela construida bajo los parámetros enunciativos del discurso epistolar, logra algo que las cartas verdaderas no pueden alcanzar, esto es, posibilita una lectura ambigua en torno al carácter unívoco del emisor y de su destinatario. Sobre este punto comenta John Berry que la novela, dentro de su experimentación genérica, ha conllevado a ciertas confusiones entre las que destaca el problema de las voces narrativas. El crítico se pre-

6 Según M. Victoria García Serrano, Poniatowska afirma haber consultado únicamente el libro de Wolfe. Mas dada la referencia a ciertos hechos que no aparecen documentadas en ese texto, se concluye que tuvo que tener conocimiento de la biografía del pintor escrita por Gladys March. 
gunta, y nosotros con él, quién escribe las cartas en realidad y para quién. La respuesta, obvia nos obliga a entrar en el reino de la especulación. Así, puede decirse que Poniatowska imagina al ser ficticio, con cierta base, como ya sabemos, y escribe, en una suerte de ventriloquia, doce cartas a Diego. Mas también puede afirmarse que Poniatowska se convierte en Angelina Beloff y le escribe las misivas al pintor. ${ }^{7}$ Igualmente, el texto ha sido visto como una sola y larga carta-diario en la cual Elena Poniatowska escribe para expresar y confrontar sus propios deseos, miedos, frustraciones y fantasías.

Junto a ello, a partir del hecho de que este texto sea considerado una novela y, a la vez, esté conformado casi en su totalidad por cartas, se genera cierta tensión formal, que concierne fundamentalmente a la idea del destinatario del mensaje textual. En una correspondencia hay un emisor y un destinatario identificables. En relación con este señalamiento Janet Altman apunta:

The epistolary form is unique among first-person forms in its aptitude for portraying the experience of reading. In letter narrative we not only see correspondents struggle with pen, ink, and paper; we also see their messages being read and interpreted by their intended or unintended recipients. The epistolary form is unique in making the reader (narrated) almost as important an agent in the narrative as the writer (narrator). (Altman 88) ${ }^{8}$

$7 \mathrm{Al}$ respecto, en el estudio de Berry encontramos transcrita una parte de una carta que la escritora mexicana le escribió al crítico en la que dice: "Cuando leí el capítulo en Bertram Wolfe sobre Angelina Beloff me detuve y empecé a escribir lo que sentía[...] En realidad fue una fusión espontánea, un chorro que salió una mañana cuando yo me sentía la esposa de Diego Rivera[...]" Más adelante repite con énfasis "yo me sentí la esposa de Diego Rivera y le dirigí esta carta a mi propio esposo" (Berry 48).

${ }^{8}$ [La forma epistolar es particular entre las formas de primera persona por su capacidad de representar la experiencia de la lectura. En la narrativa de cartas no solamente vemos la lucha del correspondiente con la pluma, la tinta y el papel, sino también vemos los mensajes siendo leídos e interpretados por los receptores intencionados, o no intencionados. La forma epistolar es única en hacer al lector (narrado) un agente de casi igual importancia en la narración como el es- 
El tono íntimo, personal y el carácter privado de la correspondencia definen al texto en sí y condicionan, por supuesto, su contenido. Una novela, en cambio, tiene en perspectiva a un destinatario que en niveles abstractos puede definirse como lector virtual, pero en términos concretos se materializa como una numerosa audiencia. Mas este texto de Poniatowska, en tanto novela epistolar, contiene un lector externo, cuya experiencia:

$[\ldots]$ is partially governed by the presence of his internal counterpart; we read any given letter from at least three points of view -that of the intended or actual recipient as well as that of the writer and our own. Even when only implied, the interpretation that the addressee would give to a letter enters into our own reading. (Altman 111) ${ }^{9}$

Todas estas consideraciones nos permiten establecer que un objeto contradictoriamente híbrido como el que estudiamos (modo de expresión privado y público) genera una tensión, que, como apunta J. Berry, el público resuelve de varias maneras. Una, adjudicando sin pensarlo mucho las cartas a la persona real de Angelina Beloff. Otra, y ésta es la más interesante, la encontramos en un grupo experimentado de lectores que no caerá en la trampa y leerá las epístolas como objetos narrativos creados por el autor. El pro-

critor (narrador)].

${ }^{9}[$... es parcialmente regida por la presencia de su contraparte interno; leemos cualquier carta desde por lo menos tres puntos de vista - el del receptor intencionado o real, el del escritor y el nuestro. Aunque solamente sugerida, la interpretación que el receptor le pudiera dar a la carta entra a nuestra propia lectura]. Se aclara que Janet Altman establece una distinción entre lo que ella llama el lector interno y el externo. El primero es "a specific character represented within the world of the narrative, whose reading of the letters can influence the writing of the letters" [las cartas toman un nuevo significado después de que leemos la nota final. Su peso específico, tal como fuese, aumenta: la soledad y el sufrimiento de Angelina y el silencio e indiferencia de Diego ya no son 'solamente' motivos literarios], mientras que el segundo lo constituimos "we, the general public, who read the work as a finished product and have no effect on the writing of individuals letters" [nosotros, el público en general, que lee el trabajo como un producto terminado y que no tiene efecto sobre la escritura de cartas individuales] (112). 
blema se va a presentar, para ambos grupos de lectores, al final de la novela, cuando una nueva voz narrativa afirma que esas cartas le deben mucho de su información" a la biografía de Diego Rivera escrita por Bertram Wolfe, con lo cual se ofrece una invitación al último grupo a volver sobre las cartas considerándolas ahora como objetos "parcialmente reales" (algo parecido pasa con el primer grupo). En consecuencia, "the letters take on new meaning after we read the final note. Their specific weight, as it were, increases: Angelina's loneliness and anguish, and Diego's silence and indifference, are no longer 'just' literary motifs" (Berry 50).

Como puede verse, la ubicación de este texto dentro del género de novela epistolar abre un espacio crítico sobre el que todavía podemos trabajar. Como bien señala Nina Scott, dicha construcción genérica se ajusta con perfección a la intención de Poniatowska; esto es, las cartas de la protagonista van a representar "la voz de una mujer y su busca de diálogo con el hombre que no solamente ama, sino que se ha constituido en su único medio de auto identificación" (Scott 415). Las cartas de Quiela constituyen más que un intento desesperado por comunicarse con un otro (no olvidemos que las mismas no son nunca respondidas) una revisión detallada, personal y muy dolorosa de un presente visualizado como cárcel por la propia protagonista, y una idealización casi histérica del pasado y del futuro. Sobre su presente agobiante, lleno de miserias y pesares, Angelina dice: "mi situación económica es terriblemente precaria y he pensado en dejar la pintura, rendirme, conseguir un trabajo de institutriz, dactilógrafa o cualquier otra cosa durante ocho horas diarias" (69-70). O, peor aún:

Pero ahora él está muerto y yo no le hago falta a nadie. Tú me has olvidado allá en tu México que tanto deseé conocer, nos separa el Atlántico, aquí el cielo es gris y allá en tu país siempre es azul y yo me debato sola sin tener siquiera el consuelo de haber trazado en estos días una línea que valga la pena. (26)

El pasado, por el contrario, al menos el que compartió con Diego, lo muestra como un espacio temporal que le permite aliviar la carga agobiante de un presente desesperanzador: "Y me refugio 
en el pasado, rememoro nuestros primeros encuentros en que te aguardaba enferma de tensión y de júbilo" (43). Incluso a la hora de evaluar sus vivencias no vacila en proclamar que: "Juntos afrontamos la vida y así pasaron diez años, los mejores de mi vida. Si se me concediera volver a nacer, volvería a escoger esos diez años, llenos de dolor y de felicidad que pasé contigo, Diego" (68).

El futuro, al igual que el pasado con Diego, lo vislumbra Quiela como la materialización de sus esperanzas, como una entidad que al ser definida por su reencuentro con Diego, aparece marcada por el deseo: "He pensado mucho en esto y creo que en tu país, donde nunca hemos vivido juntos, sería posible forjarse una vida en que no nos daríamos el uno al otro más que lo que pudiera darse espontáneamente" (64). Pero el futuro es también para Quiela la prolongación de una espera interminable, un espacio cada vez más incierto, pues sus misivas no provocan respuesta alguna en un destinatario que se muestra indiferente al dolor de una mujer que compartió con él tanta vida. Angelina, en la novela, reclama constantemente que Diego no le responda más que con remesas de dinero y cortos y escuetos recados. Ejemplo de ello lo vemos en las siguientes citas: "Ni una línea tuya y el frío no ceja[...]" (11); "[...]a quienes no me atrevo a decir que no he recibido una línea tuya" (16); "Mi mayor alegría sería ver entre mi escasa correspondencia una carta con un timbre de México, pero éste sería un milagro y tú no crees en los milagros" (24); “[...] pero mientras no tenga noticias tuyas estoy paralizada" (32); "La cosa es que no me escribes, que me escribirás cada vez menos si dejamos correr el tiempo y al cabo de unos cuantos años llegaremos a vernos como extraños si es que llegamos a vernos" (42)..$^{10}$

Las cartas, de esta manera, se convierten en una suerte de diario donde la pintora vive un proceso de revisión dolorosa de su expe-

${ }^{10}$ En relación con esta última cita, que Poniatowska tomó textualmente de una de las cartas transcritas por Beltram Wolfe en su biografía, este escritor comenta: “Anticipación profética! En 1935, impulsada por pintores mexicanos amigos suyos, consiguió ir a la tierra de sus anhelos. No buscó a Diego: no quería molestarlo. Cuando se encontraron en un concierto, Diego pasó a su lado ¡sin siquiera reconocerla!” (Wolfe 115). Esta última cita, levemente intervenida, es la que utiliza Poniatowska, a través de una voz en tercera persona, una suerte de compilador textual, para terminar la novela. 
riencia solitaria, de su lucha incesante por materializar sus deseos, los cuales la mantienen más que esclavizada, prácticamente enajenada. Dicho de otra forma, las cartas dejan de tener su función inicial en tanto que ya no conectan, sino que develan, concretizan, evidencian, una situación de absoluto desamparo. En este sentido, "la carta, desprovista de dialogismo, se convierte en metáfora de la soledad de Quiela" (Castellvi 264). ${ }^{11}$ Desde este punto de vista la carta, que siempre ha sido vista como instrumento de liberación personal en tanto que permite la expresión y la comunicación de nuestro mundo a los otros, paradójicamente deviene en la novela en herramienta de aislamiento.

De igual modo, la epístola, como constructo retórico, puede convertirse para el emisor en una suerte de estrategia textual que posibilita su autorrepresentación. De ser así, podemos afirmar que Quiela se convierte en personaje de sus propias cartas, se autoficcionaliza, y al "ser" su escritura se va auto-definiendo por medio de las cartas. Y uno no puede menos que preguntarse en torno a la configuración de la identidad que parece ser el centro de este proceso de auto-ficcionalización: ¿cuál es la Quiela que se construye?, ¿Cómo se visualiza Quiela a sí misma?, ¿qué elementos de su yo aparecen destacados? Sobre este particular, Magda Castellvi apunta que lo que encontramos en las cartas de la pintora rusa es mucho más que la proyección de un conflicto individual. Para ella, Quiela deviene en símbolo de la complicidad de la mujer en su propio proceso de victimización emocional y económica en tanto que se auto-impone un rol secundario que a la vez surge de un patrón social exterior. Señala que la protagonista de la novela "muestra rasgos marcadamente estereotípicos al amoldarse a los cánones vigentes que conceden indiscutible superioridad al hombre" (Castellvi 266). Estas observaciones se apoyan en el texto con evaluaciones que la protagonista hace de sí misma y de las experiencias

11 Sobre este asunto Altman sostiene que existe un pacto implícito en el acto epistolar mismo: "the call for response from a specific reader within the correspondent's world" [la apelación a una respuesta de un lector específico dentro del mundo del correspondiente]. Más aún: "if there is no desire for exchange, the writing does not differ from a journal, even if it assumes the outer form of a letter" [si no existe el deseo de intercambio, la escritura no es distinta a la de un diario, aunque tome la forma externa de una carta] (89). 
que vive. Así, por ejemplo, La protagonista se subestima ("yo acepto que no lo hagan por mí misma, después de todo, sin ti, soy bien poca cosa" (17), se siente culpable de la muerte de su hijo ("en estos días me he removido en mi cama torturada por el recuerdo de la muerte de mi hijo" (25), acepta con pasividad colocarse a la sombra de Diego ("incluso ahora, me conformaría con mezclar tus colores, limpiar tu paleta, tener los pinceles en perfecto estado, ser tu ayudante[...]" (65) y se desvaloriza constantemente como mujer y como pintora ("claro, prometo, prometo pero ¿prometo desde hace cuánto? Soy todavía una promesa”) (25).

No obstante, más que subrayar el elemento de complicidad de Quiela en su propia situación de dependencia, considero que la novela se inclina por una crítica al patriarcado como sistema que crea las dinámicas de opresión que a su vez posibilitan semejante situación de dependencia física, económica y emocional. Diego, entonces, se constituye en la vida de Quiela en una presencia omnipotente bajo la cual no puede más que opacarse. Bajo esta perspectiva, su silencio despiadado se constituye en una especie de omnipresencia a larga distancia del canon masculino. La pasividad y opresión de la protagonista la lleva incluso a justificar la cruel actitud de Diego: "a pesar de tu silencio que atribuyo a tu exceso de trabajo, al cambio, a los proyectos emprendidos[...]" (60). Es en este punto que la novela sitúa su crítica al sistema genérico con mayor fuerza en tanto Diego Rivera ya no es el objeto de halagos y endiosamiento como ocurre no sólo en la biografía en la que se basa la novela, sino además en el discurso historiográfico y artístico mexicanos. El Diego Rivera de la novela es disculpado dolorosamente por su protagonista, pero, sin duda, es juzgado de manera contundente por el lector.

En Querido Diego, Poniatowska elabora una cuidadosa e ingeniosa crítica a un sistema de privilegios que desde el mismo poder representacional ubica lo masculino en el centro de la producción de significados, relegando lo femenino a la espera, a la sombra. En este sentido es importante dar una mirada al proceso en apariencia neutral que resulta del hecho de que Poniatowska haya escrito una novela basada en la información expuesta por otro autor (hombre), Bertram Wolfe, en La fabulosa vida de Diego Rivera. Semejante manipulación textual configura una confrontación entre la supuesta 
objetividad de un discurso autoritario como el de Wolfe (no olvidemos la absoluta canonicidad del discurso biográfico, para muchos correlativo al discurso histórico) con la subjetividad de un discurso íntimo y personal (epistolar) como el que Poniatowska ha escogido para su novela. Pero el juego de la subversión se patentiza cuando corroboramos que la escritora mexicana copia textualmente fragmentos de las cartas transcritas por el biográfo junto con información directa que éste emite en su texto. No obstante, los resultados de ambos discursos son diferentes, en tanto este procedimiento de manipulación discursiva y los efectos que produce implican un cuestionamiento a la univocidad de un discurso que, para colmo, aparece como "fabuloso". Igualmente, la apropiación y resignificación en la novela de los fragmentos del texto escrito por el biógrafo (muchos de ellos textos "reales", como por ejemplo fragmentos de verdaderas cartas escritas por Angelina Beloff), anarquiza el espacio textual al crear un conflicto no sólo entre dos géneros por tradición evaluados de manera diferente, sino entre procesos de representación y evaluación de la "realidad histórica" también distintos.

Una revisión relativamente superficial de las diferencias fundamentales entre los enfoques de ambas obras puede apoyar lo afirmado con anterioridad. En efecto, siguiendo un poco los planteamientos de María V. García-Serrano, se pueden elaborar algunas observaciones conclusivas. Por un lado, el texto de Wolfe presenta en perfecta cronología la vida de Angelina. La novela, por el contrario, rechaza ese orden cronológico y opta por un discurso subjetivo en primera persona por medio del cual nos enteramos, dependiendo del ánimo de la protagonista, de sucesos importantes acaecidos en su vida. Como paradoja, lo único cronológico en la novela, la fecha de las cartas, en la biografía escrita por Wolfe aparece desprovisto de continuidad (sólo una fecha aparece reseñada en relación a las cartas de la pintora rusa: el 22 de julio de 1922).

Por otro lado, el papel protagónico obviamente aparece trasladado. Wolfe sólo está interesado en Angelina en tanto ésta le pueda ofrecer elementos de utilidad que le permitan una mejor y más completa configuración de su "fabuloso" personaje. Diego Rivera -puede verse desde el mismo título- aparece magnificado. Como personaje está cargado de una aureola si se quiere mítica que lo 
erige dentro del texto, y dentro de la misma historia mexicana, en una figura casi heroica. En Querido Diego Poniatowska subvierte ese orden al darle a Quiela no solamente el protagonismo, sino también entregándole la función de narradora de su propio discurso (con lo cual se manifiesta un rechazo a la autoridad de la voz masculina). Con ello, la escritora posibilita el cuestionamiento moral de una figura endiosada por el texto canónico, juicio que se evidencia con mayor fuerza con la intervención de la voz narrativa en tercera persona que cierra la novela misma (como ironía, la nota final copia textualmente parte del discurso de Wolfe, pero los resultados son con claridad diferentes).

Finalmente, Angelina Beloff es presentada de manera distinta en ambos textos. Para Wolfe la pintora carecía de verdadera afición y talento para el arte pictórico, de allí que en su texto biográfico sostenga afirmaciones como: "la vida de ella no estaba centrada en la pintura, como la de él subordinando todo a ésta" (Wolfe 115). U otra, más cruel y tajante:

Años más tarde unos amigos mexicanos la encontraron en París, todavía solitaria, todavía luchando con su pintura sin importancia y preservando en un rincón del estudio, los pinceles de Diego y las pertenencias de éste tal y como las habia dejado al marcharse. (Wolfe 115 , las cursivas son mías)

En oposición a semejante valoración, en la Quiela de Poniatowska se hace énfasis en la fuerza de su vocación juvenil y su intento desesperado de reencontrarse a sí misma a través del arte en un presente que es el resultado de una experiencia devastadora que la ha aniquilado como mujer y como artista. Así, por ejemplo, en su juventud la pintura lo dominaba todo, de allí que sostenga: "De haberlo podido me hubiera tirado a dormir en mi caballete, cada minuto perdido era un minuto menos para la pintura' (36). Asimismo, apunta la protagonista que dejar de pintar hubiera sido prácticamente imposible porque "sería tanto como perder mi alma, Diego, porque yo no vivía sino para la pintura" (38). Luego subraya su dedicación y disciplina al expresar: "Desde el primer día en que entré al atelier en París, me impuse un horario que sólo tú po- 
drías considerar aceptable [...] Nueve horas de pintura al día" (33-34).

Poniatowska, por otra parte, va más allá y pone a su personaje a vivir experiencias que tienen su correlato en anécdotas relatadas por Wolfe en relación a Diego. Dicho de otra manera, la novela opera un ejercicio de imitación que puede ser leído como una estrategia de valoración de la artista rusa. En este sentido, si ciertas experiencias vividas por Diego, tal y como lo documenta su biógrafo, son un indicio de su grandeza, entonces también lo son para la pintora, quien desde la perspectiva wolfiana carece de talento y de importancia artística. Así, podemos ver cómo la novela nos cuenta la exaltación de Quiela ante las obras de Cézanne:

Al salir del Louvre me dirigí a la Galería Vollard a ver los Cézanne y permanecí tres horas en su contemplación. Monsieur Vollard me dijo: "Je vous laisse seule" y se lo agradecí. Lloré mientras veía los cuadros, lloré también por estar sola, llore por ti y por mí, pero me alivió llorar porque comprender, finalmente es un embelesamiento y me estaba proporcionando una de las grandes alegrías de mi vida. (20)

Esta reacción tiene su anécdota paralela en la referencia que Beltram Wolfe hace a una experiencia de Diego:

En el escaparate de esta galería [Vollard] se hallaba una pintura de Cézanne; era un paisaje de un anciano fumando una pipa. Toda la mañana se quedó Diego en ese mismo sitio, caminando de un lado a otro, mirando excitado como nunca lo había estado antes. Al mediodía monsieur Vollard salió a comer y observó con suspicacia al joven admirador. Cuando regresó, Rivera todavía estaba allí. Un tanto preocupado, el propietario retiró la pintura y la sustituyó por otra, también de Cézanne. Y así transcurrió la tarde, cambiando cuadros. El emocionado espectador se emocionaba igualmente por todos. Tratábase de una revelación artística distinta por 
completo a cualquiera experiencia que en ese sentido hubiese tenido antes. (Wolfe 59) ${ }^{12}$

De igual manera, ambas obras retratan o comentan el imaginario ensanchamiento físico de que son objeto ambos personajes en momentos de inspiración y producción artística. En Querido Diego la protagonista dice:

Me volví hasta gorda Diego, me desbordaba, no cabía en el estudio, era alta como tú, combatía contra los espíritus [...] y lo recordé en ese momento porque mi caja toráxica se expandió a tal grado que los pechos se me hincharon, los cachetes, la espalda[...]. (23)

\section{En La fabulosa vida de Diego Rivera, Wolfe apunta:}

Diego en ocasiones actuaba de un modo "sumamente extraño" y, al interrogársele sobre el particular, afirmaba estar "luchando con los espíritus". A veces sentía que el estudio era demasiado pequeño para contenerlo, que llenaba la habitación comprimiendo su cuerpo en las paredes, ángulos y rincones, hasta que corría a abrir la ventana y entonces se sentía crecer al tamaño de París. (Wolfe 88)

De nuevo, la equiparación se nos presenta con un aura subversiva puesto que coloca al personaje femenino al mismo nivel que el masculino. ${ }^{13}$ Más aún: al carecer el personaje femenino de la im-

12 Se destaca que ambas experiencias, la de Diego y la de Quiela, culminaron con una enfermedad, una fiebre elevada, en los dos personajes (y la catalogación de Diego como personaje -esto es, como ficción- en este aparte es deliberada).

13 Otra interpretación sobre este aspecto puede orientarse en dirección más bien opuesta. En efecto, la equiparación de ambas experiencias puede ser vista como una dependencia más hacia Diego que la joven pintora expresa inconscientemente. Es decir, estaríamos ante una nueva manifestación del proceso de enajenación de la mujer como sujeto, la cual sólo puede expresarse como imitación del hombre, como su imagen especular deformada. No obstante, dado que este texto, profundamente contradictorio, como la mayoría de las obras de 
portancia histórica del pintor mexicano (exaltada sin cansancio por su biógrafo), las experiencias que vive, en consecuencia son también poco trascendentales. De esa manera queda neutralizado cualquier efecto "fabuloso" intrínseco en las acciones mismas. Es decir, se cuestiona el carácter supuestamente único de las experiencias de Diego, vistas en la biografía como explicaciones vivenciales de su grandeza. Lo contrario, por otra parte también es válido: si estas experiencias son tan especiales para Diego (pues por medio de ellas reconocemos su inmenso talento y su desmedida vinculación con la pintura), lo son por igual para la pintora rusa. En cualquiera de los casos estamos en un proceso que pretende borrar o aniquilar la diferencia evaluativa: o bien Diego Rivera no era tan especial como su biógrafo pretende, o bien Angelina Beloff lo era tanto como aquél. O mejor aún, estaríamos en presencia de un estándar doble típico a la hora de evaluar situaciones en las cuales el género aparece implicado: lo que es excelente en un caso, inexplicablemente es signo de mediocridad en el otro.

Quiela, pues, se nos presenta equiparada a Diego en cuanto a vocación artística se refiere. Sin embargo, Poniatowska nos muestra una diferencia fundamental entre ambos personajes. Para Angelina, la pintura y el arte significan, después de lo que ha vivido, como mujer y, sobre todo, como madre, algo más que una revelación. Lo "representado" ha dejado de ser una excusa para indagar en las posibilidades mismas de la representación artística; por el contrario, ha pasado a ser parte esencial de la misma. Por esta razón Quiela escribe lo siguiente:

Yo nunca me detuve a ver un niño en la calle (por ejemplo) por el niño en sí. Lo veía como el trazo sobre el papel; debía yo captar exactamente la pureza de la barbilla, la redondez de la cabecita [...] pero yo no veía al niño, veía sus líneas, su contorno, sus luces, no preguntaba siquiera cómo se llamaba [...] Ahora todo ha cambiado y veo con tristeza a los niños que cruzan la calle para ir a la escuela. No son dibujos, son niños de carne y hueso. (38-39)

Poniatowska, parece jugar a la transgresión, me inclino más por la posición que presento en el cuerpo central de este trabajo. 
Quiela, como los niños que ya no puede pintar, se nos muestra a los lectores como una representación de un ser humano de carne y hueso. Diego, el de Wolfe, es un ser "fabuloso", endiosado, diferente al resto de los mortales, de allí su grandeza. Irónicamente, la intervención textual efectuada por Poniatowska rescata este carácter divino en Diego, pero lo carga de connotaciones negativas, pues lo incapacita para relacionarse en el ámbito humano y sensible con la gente, en especial con su esposa e hijo.

En conclusión, en Querido Diego, te abraza Quiela Elena Poniatowska nos sumerge, ya desde su misma estructura formal, en terrenos críticos de sumo interés. Como novela epistolar nos presenta un destinatario doble y, a su vez, un emisor que parece tener más de un rostro (por no hablar de máscaras). De igual forma, las cartas nos permiten conocer paulatinamente a un sujeto que se construye durante el acto mismo de enunciación de éstas. Pero por encima de todo, estas epístolas, vistas como un discurso creado a partir de otros discursos, devienen en un juego textual que no sólo constituye un proceso de manipulación discursiva sin lugar a dudas original, sino que además, y sobre todo, revela una intención desestabilizadora y cuestionadora. En efecto, la transgresión del material documental presentado por Bertram Wolfe en su estudio biográfico de Diego Rivera puede ser visto como un intento de Poniatowska para subvertir la centralidad del discurso patriarcal. El cuestionamiento del canon se materializa en tanto que la escritora mexicana silencia la figura autoritaria de Diego para darle voz a una Ángela que es más verosímil y más real en el discurso ficcional que en el aparentemente real. Más aún, la figura de Diego Rivera pierde su carácter legendario al ser enjuiciado en lo moral de una manera indirecta pero contundente. Con ello, se desestabiliza la autoridad del discurso histórico, canonizado por la ideología patriarcal, y de su perspectiva unívoca y monumental, para dar privilegio a un discurso marginal que reivindica la subjetividad y una tradición textual usualmente evaluada como femenina.

\section{Bibliografía}

Altman, Janet. Epistolarity. Approaches to a Form. Columbus: Ohio State University Press, 1982. 
Berry, John. "Invention, Convention, and Autobiography in Elena Poniatowska's Querido Diego, te abraza Quiela." Confluencia 3.2 (1988): 47-56.

Castellvi, Magda. "Querido Diego, te abraza Quiela o la escritura de un texto femenino." Alba de América 10.18-19 (1992): 261-71.

García-Serrano, María. "Apropiación y transgresión en Querido Diego, te abraza Quiela de Elena Poniatowska." Letras Femeninas 17.1-2 (1991): 99-106.

Gilmore, Leigh. Autobiographics. A Feminist Theory of Women's Self Representation. Ithaca: Cornell University Press, 1994.

González, Beatriz. "No sólo para mujeres (el sexismo en los estudios literarios)." Escritura 16.31-32 (1991): 103-113.

González, P. y E. Ortega (eds.). La sartén por el mango. Río Piedras, Puerto Rico: Ediciones Huracán, 1985.

Jay, Paul. Being in the Text. Self-Representation from Wordsworth to Roland Barthes. Ithaca: Cornell University Press, 1984.

Jorgensen, Beth. The Writing of Elena Poniatowska. Engaging Dialogues. Austin: University of Texas Press, 1994.

Moi, Toi. Sexual Textual Politics. Feminist Literary Theory. London: Routledge, 1985.

Otero, José. "Querido Diego, te abraza Quiela, descontrucción y reconstrucción de la personalidad: lengua, estructura y símbolos del proceso." Confluencia 7.2 (1992): 75-83.

Parker, Stacey y Cristina Enríquez. "La textura del exilio: Querido Diego, te abraza Quiela; Eva Luna; Crónica de una muerte anunciada." Chasqui 22.2 (1993): 3-14.

Poniatowska, Elena. Querido Diego, te abraza Quiela. México: Biblioteca Era, 1978.

Scott, Nina. "The Fragmented Voice of Elena Poniatowska." Discurso 7.2 (1990): 411-420.

Sniader, Susan. Fictions of Authority. Women and Narrative Voice. Ithaca: Cornell University Press, 1992.

Steele, Cynthia. "La creatividad y el deseo en Querido Diego, te abraza Quiela de Elena Poniatowska." Hispamérica 14.41 (1985): 17-28.

Wolfe, Bertram. La fabulosa vida de Diego Rivera. México: Editorial Diana, 1986. 